\title{
ANALISIS PEMAHAMAN, PENERAPAN E-FAKTUR DALAM PELAPORAN PAJAK PERTAMBAHAN NILAI PADA CV. KUAT JAYA MANDIRI TANJUNGPINANG
}

\author{
Meidi Yanto \\ Program Studi S1 Akuntansi, STIE Pembangunan Tanjungpinang \\ meidiyanto@stie-pembangunan.ac.id \\ Susi Dewi \\ Program Studi S1 Akuntansi, STIE Pembangunan Tanjungpinang \\ eunice_su.1119@yahoo.com
}

\begin{abstract}
Abstrak: Wajib pajak diharuskan untuk melaporkan dan mempertanggungjawabkan perhitungan jumlah pajak yang sebenarnya terutang. Bagi Pengusaha Kena Pajak (PKP) diwajibkan untuk melaporkan dan mematuhi peraturan yang telah ditetapkan. Penelitian ini bertujuan untuk menganalisis apakah wajib pajak telah memahami sistem e-faktur dengan baik, bagaimana penerapan dalam melakukan pelaporan Pajak Pertambahan Nilai dengan menggunakan e-faktur dan apakah telah sesuai dengan peraturan perundang-undangan yang ditetapkan, dan apakah sistem e-faktur ini efektif atau tidak dalam pelaporan Pajak Pertambahan Nilai-nya. Objek penelitian penulis telah memahami dengan maksimal mengenai pemahaman sistem e-faktur tersebut, demikian juga dengan penerapan sistem e-fakturnya, dan hasil penelitan menunjukkan sistem e-faktur ini selain efektif, juga sangat efisien.
\end{abstract}

Kata kunci : E-faktur Pajak, Pajak Pertambahan Nilai, Faktur Pajak Fiktif

Abstract: Taxpayers are required to report and account for the calculation of the actual amount of tax owed. Taxable Entrepreneurs (PKP) are required to report and comply with established regulations. This study aims to analyze whether taxpayers have understood the e-invoicing system well, how to apply it in reporting Value-Added Tax using e-invoices and whether it is in accordance with the applicable laws and regulations, and whether the e-invoicing system is effective or not in reporting Value Added Tax. The object of research by the author has understood the maximum understanding of the e-invoicing system, as well as the application of the e-invoicing system, and the results of the research show that the e-invoicing system is both effective and very efficient.

Keywords: Tax E-invoice, Value Added Tax, Fictitious Tax Invoice

\section{PENDAHULUAN}

Seiring dengan peningkatan jumlah dan kebutuhan masyarakat, negara sangat membutuhkan dana pembangunan yang tidak sedikit, dimana kebutuhan akan dana pembangunan tersebut pada setiap tahunnya meningkat seiring dengan kondisi ekonomi yang semakin melemah. Kebutuhan akan dana tersebut, salah satunya diperoleh dari sumber pendapatan negara, dan pendapatan negara yang dimaksud, salah satunya adalah penerimaan dari sektor perpajakan. 
Pajak merupakan sumber utama penerimaan negara yang digunakan untuk membiayai pengeluaran negara, dan salah satunya adalah dalam hal membangun infrastruktur negara seperti membangun jalan, jembatan, sekolah, gedung, serta kepentingan negara lainnya. Berhubungan dengan meningkatnya target penerimaan pajak yang ditetapkan oleh pemerintah sendiri, maka pihak Direktorat Jenderal Pajak (DJP) yang ditunjuk sebagai suatu lembaga untuk menghimpun penerimaan pajak dalam melakukan reformasi agar penerimaan pajak dapat dipungut secara optimal, dan mengharapkan Wajib Pajak dapat patuh terhadap peraturan yang telah dibuat, agar menghindari dari kecurangan-kecurangan yang terjadi dalam upaya melaporkan pajaknya kepada negara.

Pada awalnya, Surat Pemberitahuan (SPT) ini disampaikan oleh Wajib Pajak kepada Direktorat Jenderal Pajak (DJP) melalui Kantor Pelayanan Pajak (KPP) setempat secara manual. Penyampaian dengan cara manual ini berupa hardcopy. Hardcopy yang dimaksud adalah berupa printnan kertas yang merupakan form yang disediakan oleh Kantor Pelayanan Pajak, dan harus dilaporkan langsung di Kantor Pelayanan Pajak (KPP) setempat. Namun seiring dengan semakin berkembangnya teknologi, maka Direktorat Jenderal Pajak (DJP) merancang sebuah inovasi yang merupakan salah satu alat pelayanan guna memudahkan Wajib Pajak dalam memenuhi kewajiban perpajakannya.

Salah satu pelayanan pajak yang menggunakan internet adalah penerapan system berbasis elektronik, yaitu merupakan pelayanan Surat Pemberitahuan Masa (SPT Masa) dan Surat Pemberitahuan Tahunan (SPT Tahunan) yang berbentuk form elektronik. Kemudian, teknologi elektronik ini memudahkan Wajib Pajak dalam mengelola database, karena penyimpanan dokumen Wajib Pajak telah tersimpan dalam bentuk digital. Selain itu, tingkat keamanan sebuah data juga lebih terjamin, karena semua data tersimpan didalam database ini. Pemerintah pun sangat mengharapkan agar dengan adanya kemudahan dari teknologi elektronik ini agar dapat lebih mudah dan meningkatkan kepatuhan Wajib Pajak dalam hal pelaporan pajaknya.

Pada dasarnya, proses untuk melakukan pengisian SPT melalui sistem elektronik ini tidak semudah dengan yang kita bayangkan. Karena kita harus memahami sepenuhnya mengenai mekanisme atau cara penggunaan dalam upaya penyampaian Surat Pemberitahuan pajak (SPT) secara elektronik tersebut terlebih dahulu.

Biasanya pihak Direktorat Jenderal Pajak (DJP) pasti akan menyelenggarakan sebuah seminar, agar dapat diikuti oleh wajib pajak serta kepala konsultan pajak untuk mempelajari bagaimana mekanisme 
penggunaan sistem yang dimaksud untuk melaporkan pajaknya ini.

Inovasi baru dari DJP yaitu e-Faktur yang sedang dipakai oleh PKP sampai saat ini, yang dipergunakan untuk pelaporan PPN dan sistem untuk membuka faktur pajak. Manfaat bagi Direktorat Jenderal Pajak (DJP) terkait inovasi baru ini adalah sebagai sarana untuk menekan seminimal mungkin terjadinya faktur pajak fiktif dan/atau penyalahgunaan yang dilakukan oleh pihak yang tidak bertanggung jawab atau bahkan secara sengaja, yang dapat memberikan dampak kerugian pada Negara, sehingga $e$-faktur dapat berfungsi sebagai pengawasan penggunaan faktur pajak dalam hal

kepatuhan terhadap Wajib Pajak dalam perpajakan. Serta, implementasi e-faktur akan mempermudah pengawasan yang dilakukan. Sebab, data transaksi berupa pajak masukan dan pajak keluaran akan mudah diketahui DJP sehingga proses pemeriksaan menjadi lebih cepat. Sejak bulan Juli Tahun 2016 telah ditetapkan bahwa di Tanjungpinang maupun Bintan ini sudah harus menerapkan program baru dengan nama e-Faktur yang dimaksud tadi.

Berdasarkan latar belakang dan uraian permasalahan diatas, mendorong penulis untuk melakukan penelitian lebih lanjut mengenai sejauh mana pemahaman wajib pajak terkait program e-faktur ini, bagaimana penerapan dalam pelaporan PPN dengan menggunakan e- faktur, serta seberapa efektifnya program efaktur ini menurut persepsi Wajib Pajak, dengan judul penelitian "Analisis Pemahaman, Penerapan, Dan Keefektifan E-Faktur Dalam Pelaporan Pajak Pertambahan Nilai Pada CV. Kuat Jaya Mandiri Di Tanjungpinang”.

\section{Tujuan Penelitian}

Berdasarkan latar belakang masalah dan rumusan masalah yang telah diuraikan diatas, maka tujuan yang ingin dicapai dalam penelitian ini adalah :

Untuk mengetahui apakah wajib pajak telah memahami sistem e-faktur dengan baik

Untuk mengetahui bagaimana penerapan dalam melakukan pelaporan Pajak Pertambahan Nilai dengan menggunakan efaktur dan apakah telah sesuai dengan peraturan perundang-undangan yang ditetapkan

Untuk mengetahui apakah sistem e-faktur ini efektif atau tidak dalam pelaporan Pajak Pertambahan Nilai-nya

Untuk mengetahui serta apa kelebihan dan kekurangan e-faktur dari pendapat wajib pajak.

\section{Kegunaan Penelitian}

Hasil penelitian ini penulis mengharapkan agar dapat menambah referensi tentang analisis pemahaman wajib pajak, penerapan, serta keefektifan aplikasi e-faktur dalam pelaporan Pajak Pertambahan Nilai pada salah 
satu wajib pajak badan yang akan peneliti teliti.

Bagi Perusahaan, penelitian ini diharapkan akan memberikan wawasan kepada perusahaan mengenai sadar akan kepatuhan sebagai wajib pajak dalam penerapan pelaporan pajak pertambahan nilai-nya. Tidak melakukan kecurangan yang berupa membuka faktur pajak fiktif, dan hal lainnya yang merugikan kas negara.

Bagi Peneliti, mengetahui apakah wajib pajak telah memahami dengan baik mengenai penerapan aplikasi e-faktur ini, mengetahui apakah benar-benar efektif setelah menggunakan aplikasi e-faktur ini dalam melaporkan Pajak Pertambahan Nilai SPT Masa PPNnya. Serta memberikan wawasan kepada peneliti yang lebih mengenai permasalahan yang ada dalam menggunakan sistem e-Faktur.

\section{METODE PENELITIAN}

Penelitian yang akan dilakukan oleh peneliti adalah dengan menggunakan penelitian kualitatif. Menurut Sugiyono (2011), metode penelitian kualitatif adalah metode penelitian yang berlandaskan pada filsafat post positivisme, digunakan untuk meneliti pada kondisi obyek yang alamiah, dimana peneliti adalah sebagai instrumen kunci, pengambilan sampel sumber data dilakukan secara purposive dan snowball, teknik pengumpulan dengan tri-anggulasi (gabungan), analisis data bersifat induktif atau kualitatif, dan hasil penelitian kualitatif lebih menekankan makna dari pada generalisasi.

\section{Jenis Penelitian}

Adapun data yang digunakan dalam penelitian ini, adalah data primer . Menurut Achmad Maulidi (2016) data primer adalah sumber data penelitian yang diperoleh secara langsung dari sumber aslinya yang berupa wawancara, jajak pendapat dari individu atau kelompok (orang) maupun hasil observasi dari suatu obyek, kejadian atau hasil pengujian (benda).

\section{Teknik Pengumpulan Data}

Teknik pengumpulan data yang digunakan adalah metode observasi dan metode wawancara.

\section{Teknik Analisis Data}

Analisis data adalah proses mencari dan menyusun secara sistematis data yang diperoleh dari hasil observasi, catatan lapangan dan studi dokumentasi, dengan cara mengorganisasikan data ke sintesis, menyusun kedalam pola, memilih mana yang penting dan mana yang akan dipelajari, dan membuatksimpulan sehingga mudah dipahami oleh diri sendiri dan orang lain (Sugiyono, 2009). Dalam penggunaan teknik analisis data, penulis mengacu pada teknik yang sudah umum digunakan oleh para peneliti, yakni 
teknik analisis data model interaktif yang sebagaimana dibuat oleh Miles dan Huberman. Menurut Miles dan Huberman dalam (Sugiyono, 2009) mengatakan bahwa dalam analisis data kualitatif, dapat dilakukan melalui langkah-langkah sebagai berikut: pengumpulan data, yaitu data reduction, data display, dan conclusion drawing/verification.

\section{HASIL DAN PEMBAHASAN}

\section{Pemahaman e-Faktur Pada CV. Kuat Jaya}

\section{Mandiri}

Dalam hal ini, hasil daripada wawancara akan penulis analisis apakah Bapak Sukendro Aluwie, Bapak Lukendro dan Ibu Christina memahami mengenai e-faktur. Dan, dapat dilihat bahwa mereka telah mengerti dengan baik menganai apa itu sistem e-faktur, apa tujuan adanya e-faktur serta syarat dasar untuk menggunakan sistem e-faktur.

\section{Penerapan e-Faktur Pada CV. Kuat Jaya}

\section{Mandiri}

Dalam hal ini, hasil daripada wawancara akan penulis analisis apakah Bapak Sukendro Aluwie, Bapak Lukendro dan Ibu Christina memahami bagaimana penerapan dalam efaktur. Dan, dari hasil analisis penulis, biasanya yang memproses dan menggunakan sistem e-faktur ini hanya Bapak Sukendro Aluwie dan Ibu Christina saja. Hasil analisis penulis, mereka sudah sangat menguasai sistem e-faktur ini, dalam penerapannya juga sudah mengikuti langkah-langkah yang sesuai dengan peraturan. Hal ini juga ada dikatakan oleh Ibu Christina sendiri. Bahkan pertanyaan mengenai status approval mereka juga sudah mengerti, karena bagian tersebut merupakan tahap akhir upload Faktur Pajak. Dan tahap yang paling akhir yaitu mengexport file CSV juga mereka tahu dengan jelas.

\section{Keefektifan e-Faktur Pada CV. Kuat Jaya Mandiri}

Dalam hal ini, hasil daripada wawancara akan penulis analisis apakah Bapak Sukendro Aluwie, Bapak Lukendro dan Ibu Christina sudah merasa dalam e-faktur ini sudah efektif atau belum. Dan, dari hasil analisis penulis, Bapak Sukendro, Bapak Lukendro, dan Ibu Christina sudah merasa cukup efektif bahkan lebih banyak ke efisiensinya dalam sistem efaktur ini. Dimana terdapat barcode yang sudah tidak perlu tandatangan basah lagi, lebih hemat kertas karena sudah dalam bentuk PDF, aplikasi sudah otomatis membuat formulir SPT masa PPN sehingga PKP tidak perlu kerja sekali lagi untuk mengisi form, selain itu juga NSFP yang sudah go online sehingga lebih memudahkan PKP juga. Hanya saja ada sedikit keluhan dari Ibu Christina mengenai kurangnya e-faktur ini, yaitu tidak bisa mendeteksi kesalahan pada angka PPN yang bukan 10\% dari angka DPP, dan satu masalah lagi terkait masalah pengkreditan Faktur Pajak 
Masukan yang hanya dapat dikreditkan terhitung 3 bulan kedepan, sayangnya e-faktur tidak dapat mendeteksi, dan dapat dilakukan pengupload.

\section{Kelebihan dan Kekurangan e-Faktur Menurut CV. Kuat Jaya Mandiri}

Dalam hal ini, hasil daripada wawancara akan penulis analisis pendapat dari direktur dari CV. Kuat Jaya Mandiri itu sendiri mengenai kelebihan dan kekurangan daripada sistem e-faktur itu sendiri. Berikut akan penulis jabarkan:

\section{Kelebihan :}

Dapat menghindari adanya Faktur Pajak Fiktif, adanya barcode, sehingga tidak perlu tandatangan basah, keamanan dari segi data terjamin, menghemat biaya dan waktu, mudah di operasikan, dan lebih efisien

Kekurangan :

Waktu proses NTPN di sistem e-faktur membutuhkan jarak waktu yang cukup lama untuk bisa proses, data yang telah diupload, tidak dapat diubah lagi, tidak bisa mendeteksi perbedaan angka 10\% PPN dari angka DPP, tidak dapat mendeteksi pengkreditan Faktur Pajak yang lebih dari masa pajak yang telah ditentukan hanya 3 bulan kedepan saja, harus koneksi dengan internet.

\section{PENUTUP}

\section{Kesimpulan}

Berdasarkan hasil penelitian yang telah penulis analis dan akan penulis jabarkan sebagai berikut :

Pemahaman sistem e-faktur pada CV. Kuat Jaya Mandiri sudah sangat bagus. Hal ini dapat dilihat dari pengertian e-faktur menurut pemahamannya, kemudian juga mengetahui apa tujuan daripada e-faktur, serta syarat dasar dari e-faktur.

Penerapan sistem e-faktur pada CV. Kuat Jaya Mandiri sudah efisien. Hal ini dapat diketahui dari jawaban narasumber sudah mengarah bahwa sistem e-faktur ini sudah tepat guna, berhasil guna, dan juga sudah menunjang tujuan daripada pemberlakuan sistem e-faktur pajak itu sendiri.

Efektivitas dan efisiensi daripada penerapan sistem e-faktur PPN ini dapat meningkatkan kepatuhan PKP. Ini terlihat dari peraturan yang mengharuskan semua PKP wajib menggunakan sistem e-faktur, dan jawaban dari narasumber juga mengarahkan bahwa penggunaan efaktur memberikan kemudahan sehingga mereka mampu melakukan kewajiban perpajakan (kalkulasi/hitung total dari Faktur Pajak Keluaran maupun Masukan, sistem pembayarannya, permintaan NSFP, dan juga dalam hal pelaporan) secara tepat waktu. 
Dari nara sumber mengatakan bahwa kendala di penggunaan e-faktur adalah permasalahan di koneksi internet, dan tidak dapat deteksinya salahnya nominal $10 \%$ PPN dari angka DPP.

\section{Saran}

Berdasarkan hasil penelitian dari wawancara, maka penulis bermaksud memberikan saran yang berharap dapat bermanfaat bagi pihak perusahaan maupun bagi peneliti selanjutnya. Saran penulis sebagai berikut :

Bagi Pihak Perusahaan, untuk penerapan efaktur memang sudah cukup, tapi disarankan untuk penyetoran kurang bayar PPN nya 2 hari sebelum lapor, dan jangan terlalu di akhir bulan baru melaporkan SPT Masa PPN nya. Menimbangkan dari masalah NTPN yang dikemukakan, sehingga tidak terjadi telat lapor SPT Masa PPN. Dan juga masalah koneksi jaringan internet yang dapat mengakibatkan telatnya lapor pajak.

Bagi Peneliti Selanjutnya, penulis berharap untuk penelitian selanjutnya disarankan untuk mengambil beberapa perusahaan untuk diteliti agar memperkuat hasil penelitian.

Bagi Pihak Direktorat Jenderal Pajak, penulis berharap pihak DJP dapat mengupdate aplikasi e-faktur mengenai harus dapat mendeteksinya 10\% PPN dari angka DPP, serta permasalahan lain yang telah menjadi kendala bagi wajib pajak selama ini.

\section{DAFTAR PUSTAKA}

Afrika, R., Betri, \& Fajriana, I. (2011). Pengaruh Penerapan E-SPT PPN Terhadap Kepuasan Wajib Pajak Dalam Penggunaan E-SPT PPN (Studi Kasus Pada Pengusaha Kena Pajak Di KPP Pratama Palembang Ilir Barat), 10.

Anzeli Maria, Inggriani Elim, N. S. B. (2018). Analisis Penerapan E-Faktur Dalam Prosedur Dan Pembuatan Faktur Pajak Dan Pelaporan SPT Masa PPN Pada CV. Wastu Citra Pratama. Riset Akuntansi Going Concern, 13(3), 11.

Christin, L. (2017). Pengaruh Penerapan EFaktur Dan E-SPT PPN Terhadap Kepatuhan Perpajakan Pengusaha Kena Pajak Dengan Kemampuan Menggunakan Internet Sebagai Variabel Moderating. Akuntansi Perpajakan, Vol.2(No.1), 10.

Handayani1, K. P., \& Supadmi2, N. L. (2013). Pengaruh Efektivitas E-SPT Masa PPN Pada Kepatuhan Wajib Pajak Badan Di KPP Pratama Denpasar Barat. Akuntansi, 4(1), 20.

Isroah. (2013). Perpajakan. Yogyakarta.

Juhardini, R. (2013). Electronic Effectiveness Notice Of Value Added Tax (E-SPT PPN) In The Tax Office (KPP) Primary Surabaya Sawahan, 13.

Kurnia Ramadhan, M., \& Pratomo, D. (2012). Pengaruh Penerapan E-SPT PPN Terhadap Efisiensi Pengisian SPT Menurut Persepsi Wajib Pajak. (Survey Terhadap Pengusaha 
Kena Pajak Pada KPP Pratama Cibeunying).

Kevin, L., Lintje, K., \& Pusung, R. (2017). Analisis Penerapan E-Faktur Pajak Dalam Upaya Meningkatkan Kepatuhan Pengusaha Kena Pajak Untuk Pelaporan SPT Masa PPN Pada KPP Pratama Manado. Emba, Vol.5(No.2), 10.

Mardiasmo. (2018). Perpajakan (2018th ed.). Yogyakarta: ANDI.

Mahyudin, D. M. (2015). Analisis Kepatuhan Wajib Pajak Dengan Diterapkannya Program E-SPT Dalam Melaporkan SPT Masa PPN Pada KPP Pratama Bitung. Emba, Vol.3(No.1), 8.

Peraturan Direktur Jenderal Pajak Nomor PER-16/PJ/2014 tentang Tata Cara Pembuatan Dan Pelaporan Faktur Pajak Berbentuk Elektronik.

Prianata, D. (2012). Perpajakan Indonesia. Jakarta.

Resmi, S. (2015). Teori dan Kasus Perpajakan. Jakarta: Salemba Empat.

Saputra, I. (2017). Pengaruh Sosialisasi Dan Penerapan E-Faktur PPN Terhadap

Efisiensi Pengadministrasian Faktur Pajak (Menurut Persepsi Pengusaha Kena Pajak yang Terdaftar di KPP Pratama Banjarmasin). Ekonomi Dan Bisnis, Vol. 10(No. 2), 13.

Sukardji, U. (2009). Pajak Pertambahan Nilai (PPN) (Revisi 200). Jakarta.
Supramono, \& Woro Damayanti, T. (2015). Mekanisme \& Perhitungan Perpajakan Indonesia. Yogyakarta: ANDI.

Sutedi, A. (2016). Hukum Pajak. Jakarta: Sinar Grafika.

Temesgen, G. (2013). Problems And Prospects Of Value-Added Tax (Vat) Implementation In Tigrai Regional State. Accounting, Vol.1(No.1), 16. 